\title{
On the Convention Bureau's Evaluation of its Regional Characteristics and Convention Facilities
}

\author{
Hidekazu Iwamoto*, Tokuro Matsuo', \\ Toshikazu Fukushima ${ }^{\ddagger}$ Norihisa Komoda ${ }^{\S}$
}

\begin{abstract}
The convention industry produces great economic impact due to the fact that when conferences are held, delegates who participate stay longer than pleasure travelers, or those with other purposes. Many different stakeholders are involved in the convention industry as it is an essential factor in promoting inbound tourism in Japan. This study focuses on the evaluation of the convention bureau, taking into account its regional characteristics and convention facilities. A questionnaire survey was conducted at the 24th international Meetings Expo (IME 2014) held on December 9-10, 2014, at the Tokyo International Forum, Japan. Researchers distributed questionnaires directly to the convention bureaus during the IME 2014. The respondents' evaluation about their region and convention center was measured. Furthermore, the binary logistic regression was adopted to clarify how the duration of service affected their evaluation. This model is utilized in the case of a situation where mainly two possible results are expected. The results showed that there were some significant differences in duration of service.
\end{abstract}

Keywords: Convention bureau, Convention industry, Questionnaire survey,

\section{Introduction}

In 2015, the total number of foreign visitors in Japan reached over 19.7 million, the highest growth rate recorded since 1964. In the tourism industry, the convention is growing as one of the most important segments. The convention industry does not only benefit the local economy, but also acts as economic hubs to surrounding areas [1]. In addition, the convention industry produces great economic impact and is rapidly diversifying.

The convention industry brings about great economic impact because delegates who participate in the convention stay longer than pleasure travelers who have other purposes [2]. This triggers convention host cities to compete to attract more profitable exhibitions. With the tightening competition of international convention destinations among other competitive cities, marketing approaches to promote international conferences in the global market have become rapidly sophisticated and diversified. Such movement calls for the need for the Japanese gov-

\footnotetext{
* Josai International University, Chiba, Japan

$\dagger$ Advanced Institute of Industrial Technology, Tokyo, Japan

$\$$ Conference Service Tokyo Inc, Tokyo, Japan

$\S$ Code Solution K.K, Osaka, Japan
} 
ernment to take action.

Among the stakeholders, the convention bureau plays an important role to attract convention business in Japan. However, research on the convention industry in Japan is still limited, and there are very few empirical studies using quantitative data. Therefore, this study focuses on the evaluation of the convention bureau and discusses the differences with regards to the duration of the bureau's service.

The findings of this study help us not only to identify the current evaluation of convention bureaus regarding the regional characteristics and its convention facilities, but also to make clear of how the duration of service affects the evaluation.

\section{Literature review}

\subsection{Role of convention bureaus}

Convention bureaus have been regarded as important organizations in the tourism industry [3]. This is because convention bureaus can help planners as an encouraging partner and act as the liaison between prospective visitors to the destination as well as to the business people who will interact with visitors [4]. As for the provision of the highest level of service quality, convention bureaus can be a critical factor in an environment where competition among destinations for conventions intensifies [5]. Moreover, convention and visitor bureaus provide official information to the future visitors [6]. They make an effort to collect useful information for presentations to the planners. Thus, convention bureaus play an important role in various aspects. If convention delegates feel uneasy venturing outside the center because of the uninviting surrounding, this may actually result in a negative perception of the city as a whole [7]. The experiences of convention bureaus hold one of the key components of success in the convention industry.

There have been a small number of studies that focus on convention bureaus. Iwamoto et. al. [8] conducted a questionnaire survey with convention bureaus to clarify the current advantages and weak points of each city in which the convention is held. The results showed that major advantages are: good public security, richness in historical properties, and unique culture. On the other hand, weak points are: English proficiency of officers, English Web pages, and multilingual display in local areas. Moreover, Iwamoto et. al. [9] discussed the evaluation between non-experienced and experienced convention bureaus with regards to the regional characteristics that each region has. The results showed that the experienced tended to have high awareness of providing local information, while the non-experienced tended to have high awareness of providing the best service as hospitality in the local area.

\subsection{Important factors of region and convention facilities}

Some important factors regarding the regional characteristics and convention facilities have been clarified in the previous studies.

Chen [10] classified five items in the process of convention site selections; meeting and accommodation facilities, costs, site environment, local support, and extra conference opportunities and found meeting accommodation facilities and site environmentally important items. Moreover, Crouch and Bitchie [11] regarded accessibility, local support, extra-conference opportunities, accommodation facilities, meeting facilities, information, and site environment as important factors.

Go and Govers [12] conducted a study to find out key success factors if meeting planners selected Asian countries as their destinations. The results of the questionnaire showed that re- 
spondents regarded the capacity of facilities, quality of service, accessibility and price as most important. Lee [13] found roads and accessibility were highly valued by the organizers. In addition, the staff's fluency in major languages was also one of the necessary elements for conference organizers. Moreover, Qu, Li, and Chu [14] examined satisfaction levels of Hong Kong as an international conference destination. As a result, all respondents evaluated 20 site selection criteria. Among them, modern-audio-visual equipment, modern hotel facilities, and accessibility were ranked as the top three.

Kim, Guo, and Agrusa [15] regarded inexpensive travel cost, level of economic development, beautiful scenery, safety, good place for shopping, different cultural and historical resources, good weather, good leisure and recreation facilities, easiness to arrange travel plans, and well-equipped tourism facilities as important factors. Accessibility, capacity of accommodation facilities, local support, multi-language, and site environment as important factors are highly featured in the previous studies, thus proving the importance to consider these important factors to attract the international convention.

Though the previous studies point out that convention bureau plays a pivotal role throughout convention, there are very few studies on the topic. Therefore, this study focuses on its regional characteristics and convention facilities and sees the differences in the convention bureau's evaluation by duration of service.

\section{Methodology}

\subsection{Overview}

The questionnaire survey was conducted at the 24th international Meetings Expo (IME 2014) held on December 9-10, 2014, at the Tokyo International Forum, Japan. IME is known as the only domestic tradeshow dedicated to MICE. There were 2050 visitors and 1402 exhibitors attending the IME 2014. The target population in the present study consists of convention bureaus exhibited at IME 2014. This questionnaire is to examine the convention bureaus' perceptions of their regions and convention centers.

\subsection{Data collection}

Researchers distributed questionnaires directly to the convention bureaus during the IME held on Dec 10,2014. The questionnaire was composed of two parts.

In part one, respondents were asked 21 questions to rate characteristics of their region and convention centers. The questions consisted of 7 domains: area information, transportation system, local service, local area, condition of sites, convention facilities, and convention service.

The part asks the respondents about the characteristics of their region and convention center and was measured on a 5-point Likert scale ranging from 1 (strongly disagree) to 5 (strongly agree). These items were based on a literature review dealing with the importance of geographic conditions and convention centers.

Part two of the questionnaire included demographic information regarding the respondents' background such as: gender, age, workplace, job position in the convention bureau, years of experience in the convention industry, and number of international conventions they had hosted before.

During the IME 2014, researchers collected 118 questionnaires, out of which 78 questionnaires were used for the analysis. Reasons for the elimination of these questionnaires from the analysis included partially incomplete answers. 


\subsection{Data analysis}

Data analysis was conducted in three steps. First, descriptive statistics of demographic factors were analyzed. Second, descriptive statistics of each respondent's evaluation were analyzed. This study clarifies the differences in the convention bureau's evaluation by duration of service, so researchers analyzed the item, 'duration of service in convention industry' in the questionnaire survey. Finally, a binary logistic regression was conducted to clarify the differences in the convention bureaus' evaluation by duration of service.

Logistic binary regression is used for a two-value response. This model is utilized in the case of a situation where two possible results are expected. This study focuses on whether there would be any variables showing significant differences in the convention bureau's evaluation by duration of service.

$$
\pi i=\operatorname{Pr}\left(Y_{i}=1 \mid X_{i}=x_{i}\right)=\frac{\exp \left(\beta_{0}+\beta_{1} x_{i}\right)}{1+\exp \left(\beta_{0}+\beta_{1} x_{i}\right)}
$$

Figure 1. Equation of binary logistic regression

$\pi$ is the probability that an observation is in a specified category of the binary Y variable. With the logistic model, estimates of $\pi$ from equations like the one above will be between 0 and 1 .

In the questionnaire survey, researchers classified respondents into two groups: the respondents with less than 2 years of work experience and the respondents with more than 3 years of work experience. The number of respondents with less than 2 years of work experience was 37 , while the number of respondents with more than 3 years of work experience was 41 . The numbers of both groups were almost equal.

\section{Results}

\subsection{Characteristics of respondents}

The demographic profiles of the respondents are shown in Table 1. The gender composition of the respondents was $29 \%$ female and $71 \%$ male. $28 \%$ of the respondents were between the ages of 30-39, 40-49, and 50-59 respectively. Around $70 \%$ of the respondents in the questionnaire survey were male.

The section of the respondents' workplace included, 'Hokkaido \& Tohoku', 'Kanto \& Koshinetsu', 'Chubu and Hokuritku', 'Chugoku \& Shikoku', and 'Kyushu \& Okinawa'. While the percentages, in order were: $18 \%, 14 \%, 32 \%, 23 \%$, and $13 \%$ respectively. There were a few questionnaires of convention bureaus from Kinki, but these were partially incomplete answers.

In terms of job position in the convention bureau, $37 \%$ of the respondents were managers, $14 \%$ of the respondents were assistant managers, $41 \%$ of the respondents were staff, only $3 \%$ of the respondents were executive officers, and $5 \%$ of the respondents were others, concluding that the highest group of the respondents were staff members.

Regarding the duration of service in the convention industry, $21 \%$ of the respondents were 'less than one year', $27 \%$ of the respondents were 'one to two years', $13 \%$ of the respondents were 'three to four years', $23 \%$ of the respondents were 'five to ten years', and $17 \%$ of the respondents were 'more than ten years'. Those who answered 'one to two years' were slightly 
higher than other items, while those who answered 'three to four years' were the lowest.

According to the demographic profiles, the age group of the respondents was between the 30 s and 50s and many of them who participated in the IME 2014 were managers or staff. Although $40 \%$ of the respondents were staff members, the duration of service in the convention industry was highly variable.

Table 1. Demographic information of respondents $(\mathrm{N}=78)$

\begin{tabular}{|c|c|c|}
\hline Variables & Frequency (n) & Percent (\%) \\
\hline \multicolumn{3}{|l|}{ Gender } \\
\hline Female & 23 & 29 \\
\hline Male & 55 & 71 \\
\hline \multicolumn{3}{|l|}{ Age } \\
\hline $20 \mathrm{~s}$ & 9 & 12 \\
\hline $30 \mathrm{~s}$ & 22 & 28 \\
\hline $40 \mathrm{~s}$ & 22 & 28 \\
\hline $50 \mathrm{~s}$ & 22 & 28 \\
\hline $60 \mathrm{~s}$ and over & 3 & 4 \\
\hline \multicolumn{3}{|l|}{ Workplace } \\
\hline Hokkaido \& Tohoku & 14 & 18 \\
\hline Kanto \& Koshinetsu & 11 & 14 \\
\hline Chubu and Hokuritku & 25 & 32 \\
\hline Kinki & 0 & 0 \\
\hline Chugoku \& Shikoku & 18 & 23 \\
\hline Kyushu \& Okinawa & 10 & 13 \\
\hline \multicolumn{3}{|c|}{ Job position in convention bureau } \\
\hline Executive officer & 2 & 3 \\
\hline Manager & 29 & 37 \\
\hline Assistant manager & 11 & 14 \\
\hline Staff & 32 & 41 \\
\hline Other & 4 & 5 \\
\hline \multicolumn{3}{|c|}{ Duration of service in convention industry } \\
\hline Less than one year & 16 & 21 \\
\hline One to two years & 21 & 27 \\
\hline Three to four years & 10 & 13 \\
\hline five to nine years & 18 & 23 \\
\hline More than ten years & 13 & 17 \\
\hline
\end{tabular}

Table 2 presents the duration of the service in the convention industry by each age group. 
The respondents who have less than one year of work experience were: four in their 20s, four in their $30 \mathrm{~s}$, three in their $40 \mathrm{~s}$, four in their $50 \mathrm{~s}$, and one in their $60 \mathrm{~s}$ and over respectively. There were 21 respondents in the category of one to two years of work experience. The respondents of one to two years of work experience were the largest in number for the duration of service.

Those who have one to two years of work experience were: four in their 20's, eight in their 30's, three in their 40's, six in their 50's, and one in their 60's and over. Four in their 30s, three in their $40 \mathrm{~s}$, and three in their $50 \mathrm{~s}$ had three to four years of work experience in the convention industry. The respondents who had five to nine years of work experience were two in their 20s, four in their 30s, eight in their 40s, three in their 50s, and one in their $60 \mathrm{~s}$ and over. There were 13 respondents, mostly in their 40s and 50s who had ten years of work experience in the convention industry.

Table 2. Duration of service in convention industry by age

\begin{tabular}{|l|r|r|r|r|r|r|}
\hline \multicolumn{7}{|l|}{ Duration of service in the convention industry } \\
\hline Age & less than one & One to two & Three to four & Five to nine & More than ten & Total \\
\hline $20 \mathrm{~s}$ & 4 & 3 & 0 & 2 & 0 & 9 \\
\hline $30 \mathrm{~s}$ & 4 & 8 & 4 & 4 & 2 & 22 \\
\hline $40 \mathrm{~s}$ & 3 & 3 & 3 & 8 & 5 & 22 \\
\hline $50 \mathrm{~s}$ & 4 & 6 & 3 & 3 & 6 & 22 \\
\hline $60 \mathrm{~s}$ and over & 1 & 1 & 0 & 1 & 0 & 3 \\
\hline \hline Total & 16 & 21 & 10 & 18 & 13 & 78 \\
\hline
\end{tabular}

\subsection{Measurement of each convention bureau's evaluation}

Table 3 presents the descriptive analysis of 21 items regarding the characteristics of their region: area information, transportation system, local service, and local area. Each item was measured on a five-point Likert scale with 1 representing 'strongly disagree' and 5 representing 'strongly agree'; 3 represents the midpoint value. 'Professional congress organizer' mentioned in domain 3 , is a job that specializes in the creation, production and implementation of conferences and events.

In terms of "area information", the higher mean score was 'Q1 variety of local information on the web' $(M=2.68)$. Another item, 'Q2 variety of hotel information on the web' received a mean score of 2.56. Regarding "transportation", the highest mean score was 'Q7 reasonable local transportation fares' $(M=3.22)$; the second highest mean score was 'Q5 reasonable transportation fares from airport' $(M=3.13)$; the third highest mean score was 'Q6 Easy access to host cities' $(M=3.09)$. This item was highest standard deviation value $(\mathrm{SD}=1.240)$ in all items. The other two items, 'Q3 number of direct flight from abroad' $(M=2.30)$ and 'Q4 convenient transportation system from airport' $(M=2.92)$, were lower than the mean score of 3.00.

For "local service", "Q8 level of local PCO" and "level of local catering service" received mean scores of 2.54 and 3.00 respectively.

Concerning "local area", 'Q11 safety and security of the destination \& venue' $(M=4.44)$ was the highest value in all items. 'Q10 a variety of multilingual sign' and 'Q12 friendly attitudes of residents for visitors' received mean scores of 2.55 and 2.97. For "conditions of site", 'Q14 easy access from the convention center to downtown' $(M=3.58)$ was the highest value. 'Q13 easy access from airport to the convention center' and 'Q15 sufficient number of accommodation nearby convention centers' received mean scores of 3.12 and 3.22. Regarding "convention facilities", 'Q18 cleanliness of venue's restroom' was the highest value. The second highest value 
was 'Q16 universal design for people with disability' and the third highest value was 'availability of day care center for kids'.

Concerning "convention service", all three items were lower than the mean score of 3.00 . 'Q19 a variety of multilingual sign in convention center', 'Q20 availability of Wi-Fi', and 'Q21 availability of free space' received a mean score of $2.76,2.99$, and 2.86 respectively.

Table 3. Measurement of the respondents' evaluation

\begin{tabular}{|c|c|c|c|}
\hline \multicolumn{2}{|r|}{ Question items } & Mean & SD \\
\hline \multicolumn{2}{|c|}{ Domain 1: Area information } & & \\
\hline 1 & Variety of local information on the Web & 2.68 & 1.000 \\
\hline 2 & Variety of hotel information on the Web & 2.56 & 0.906 \\
\hline \multicolumn{2}{|c|}{ Domain 2: Transportation system } & & \\
\hline 3 & Number of direct flights from abroad & 2.30 & 1.070 \\
\hline 4 & Convenient transportation system from airport & 2.92 & 1.114 \\
\hline 5 & Reasonable transportation fares from airport & 3.13 & 1.144 \\
\hline 6 & Easy access to host cities & 3.09 & 1.240 \\
\hline 7 & Reasonable local transportation fares & 3.22 & 1.002 \\
\hline \multicolumn{2}{|c|}{ Domain 3: Local service } & & \\
\hline 8 & Level of local Professional Congress Organizer (PCO) & 2.54 & 1.235 \\
\hline 9 & Level of local catering service & 3.00 & 0.912 \\
\hline \multicolumn{2}{|c|}{ Domain 4: Local area } & & \\
\hline 10 & A variety of multilingual signs & 2.55 & 0.989 \\
\hline 11 & Safety and security of the destination $\&$ venue & 4.44 & 0.731 \\
\hline 12 & Friendly attitudes of residents for visitors & 2.97 & 0.967 \\
\hline \multicolumn{2}{|c|}{ Domain 5: Conditions of site } & & \\
\hline 13 & Easy access from airport to convention center & 3.12 & 1.081 \\
\hline 14 & Easy access from convention center to downtown & 3.58 & 1.087 \\
\hline 15 & Sufficiant number of accommodation nearby convention center & 3.22 & 1.065 \\
\hline \multicolumn{2}{|c|}{ Domain 6: Convention facilities } & & \\
\hline 16 & Universal design for people with disability & 2.94 & 0.873 \\
\hline 17 & Availability of day care center for kids & 2.44 & 0.815 \\
\hline 18 & Cleanliness of venue's restroom & 3.62 & 0.970 \\
\hline \multicolumn{2}{|c|}{ Domain 7: Convention service } & & \\
\hline 19 & A variety of multilingual sign in convention center & 2.76 & 0.983 \\
\hline 20 & Availability of Wi-Fi & 2.99 & 1.111 \\
\hline 21 & Availability of free space & 2.86 & 0.893 \\
\hline
\end{tabular}




\subsection{Multivariate regression}

Table 4 shows the differences in their opinions toward sets of questions presented to two groups: the respondents with less than 2 years of work experience and the respondents with more than 3 years of work experience.

Coefficients are the numbers by which the variables in an equation are multiplied. Z-value is a test statistic for Z-tests that measure the difference between an observed statistic and its hypothesized population parameter in units of the standard deviation. In addition, the P-value is a probability that measures the evidence against the null hypothesis.

Table 4. Difference in the convention bureau's evaluation by duration of service

\begin{tabular}{|c|l|r|r|r|r|r|}
\hline \multicolumn{1}{|l|}{ Predictor } & Coef & SE Coef & \multicolumn{1}{|c|}{$\mathbf{Z}$} & \multicolumn{1}{c|}{ P } & Odds \\
\hline Constant & -1.67830 & 3.36280 & -0.50 & 0.618 & \\
\hline 1 & Local information & -1.05560 & 0.690018 & -1.53 & 0.126 & 0.35 \\
\hline 2 & Hotel information & 1.56102 & 0.808873 & 1.93 & 0.054 & 4.76 \\
\hline 3 & Direct flight from abroad & -0.58098 & 0.455364 & -1.28 & 0.202 & 0.56 \\
\hline 4 & Convenient transportation & -0.02940 & 0.519350 & -0.06 & 0.955 & 0.97 \\
\hline 5 & Reasonable transportation & 0.55665 & 0.481554 & 1.16 & 0.248 & 1.74 \\
\hline 6 & Easy access to host cities & 0.31842 & 0.496308 & 0.64 & 0.521 & 1.37 \\
\hline 7 & Local transportation & -1.23289 & 0.522713 & -2.36 & 0.018 & 0.29 \\
\hline 8 & Local PCO & 0.18319 & 0.348272 & 0.53 & 0.599 & 1.20 \\
\hline 9 & Local catering service & -0.95146 & 0.486147 & -1.96 & 0.050 & 0.39 \\
\hline 10 & Multilingual sign & 0.03325 & 0.452879 & 0.07 & 0.941 & 1.03 \\
\hline 11 & Safety and security & 0.60098 & 0.534071 & 1.13 & 0.260 & 1.82 \\
\hline 12 & Friendly attitudes & 0.14203 & 0.417044 & 0.34 & 0.733 & 1.15 \\
\hline 13 & Easy access to convention center & 0.44303 & 0.519048 & 0.85 & 0.393 & 1.56 \\
\hline 14 & Easy access to downtown & -0.45355 & 0.445200 & -1.02 & 0.308 & 0.64 \\
\hline 15 & Accommodation nearby convention center & -0.19628 & 0.414560 & -0.47 & 0.636 & 0.82 \\
\hline 16 & Universal design for disabled people & -1.53787 & 0.743873 & -2.07 & 0.039 & 0.21 \\
\hline 17 & Day care center for kids & 0.10314 & 0.640599 & 0.16 & 0.872 & 1.11 \\
\hline 18 & Cleanliness of venue's restroom & 2.03227 & 0.599640 & 3.39 & 0.001 & 7.63 \\
\hline 19 & Multilingual sign in convention center & 0.32726 & 0.583813 & 0.56 & 0.575 & 1.39 \\
\hline 20 & Wi-Fi & -1.14385 & 0.782206 & -1.46 & 0.144 & 0.32 \\
\hline 21 & Free space & 0.520823 & 1.74 & 0.082 & 2.47 \\
\hline
\end{tabular}

Regarding 'Q7 reasonable local transportation fares', the respondents with less than two years of work experience had more positive opinions than the respondents with more than three years of work experience. The $\mathrm{P}$ value was 0.018 , showing a significant difference in the opinion of both groups. In terms of ' $\mathrm{Q} 9$ local catering service', the respondents with less than two years of work experience had more positive opinions than the respondents with more than three years of work experience. In Q9, the P value was 0.050 , showing a significant difference in the opinion of both groups.

Concerning 'Q16 universal design for people with disabilities', the respondents with less than 
two years of work experience had more positive opinions than the respondents with more than three years of work experience. The $\mathrm{P}$ value was 0.039 , showing a significant difference in the opinion of both groups. On the other hand, regarding 'Q18 cleanliness of venue's restroom', the respondents with more than three years of work experience had more positive opinions than the respondents with less than two years of work experience. In Q18, the P value was 0.001, showing a significant difference in the opinion of both groups.

There were no significant differences of the respondents' opinions on the other 17 items in both groups, indicating similarities in their opinions.

\section{Discussion}

The findings here indicate that 'Q11 safety and security of the destination \& venue' showed an exclusively high mean score. Generally speaking, Japan is seen to be a safe country so it is not just limited to specific locations and convention centers.

Convention bureaus evaluate some items below the mean score of 3.0, so it is still necessary to take sufficient measures against area information such as variety of hotel information on the web, local service such as level of local professional congress organizer (PCO), local area such as a variety of multilingual sign, convention facilities such as available of day care center for kids and introduce free Wi-Fi in each major region where tourists visit. Moreover, tourist maps or guidelines written in multiple languages should be provided for the tourists.

In the multivariate regression, the respondents with less than two years of work experience had more positive opinions than those with more than three years of work experience. Particularly in some aspects such as: 'reasonable local transportation fares', 'level of local catering service' and 'universal design for people with disability'.

The respondents with less than two years of work experience may believe that their region and convention centers are superior to other regions and convention centers. On the other hand, it seems that the respondents with more than three years of work experience do not believe that there are remarkable parts in their region and convention centers in particular, compared to other regions and convention centers.

Regarding 'cleanliness of venue's restroom' there was only one significant difference that the respondents with more than three years of work experience had a positive opinion than those with less than two years of work experience. There is a possibility that the respondents with more than three years of work experience had positive opinions about the cleanliness of the venue's restroom because they may believe that it is important to enhance the clean image of not only the convention center, but also their areas.

The result showed that the longer the duration of service in the convention industry, the more familiar the respondents are with other regions and convention centers. This is most likely because the respondents who have worked in the convention industry for many years are less likely to overestimate their regions and convention centers. Therefore, it is important for the convention bureaus to share the information amongst each other and have an opportunity to reconsider the most remarkable things in their regions and convention centers.

It is important to acknowledge that this study has some limitations. In order to secure the valid responses, researchers had to eliminate the invalid responses despite the fact that 118 questionnaires were collected. Moreover, this study divided respondents into two groups; respondents with less than two years of work experience and more than three years of work experience, but it is difficult to observe the borderline that respondents change their opinions though there are some significant differences in the two groups. Therefore, it is still unclear whether the duration of service affects the evaluation, which emphasizes the necessity to continue with a 
further study to analyze the differences in future research.

\section{References}

[1] C. K. H. Lau, S. Milne, and C. S. Johnston, " MICE, ICT and local economic development: The case of Te Kahurangi, New Zealand," Journal of Convention \& Event Tourism, vol.7, no.1, pp. $61-75,2005$.

[2] S. S. Kim, K. Chon, and Y. K. Chung, "Convention industry in South Korea: an economic impact analysis," Tourism Management, vol. 24, no. 5, pp. 533-541, 2003.

[3] M. Ha, and C. Love, " Exploring content and design factors associated with convention and visitors bureau web site development: an analysis of recognition by meeting managers," Journal of Convention \& Event Tourism, vol. 7, no. 1, pp. 43-59, 2005.

[4] D. Koutoulas, "Operational and financial characteristics of convention and visitors Bureaux," Journal of Convention \& Event Tourism, vol. 7, no.3/4, pp. 139-155, 2005.

[5] K. Weber, and W. S. Roehl, "Service quality issues for convention and visitor bureaus," Journal of Convention \& Exhibition Management, vol. 3, no.1, pp.1-19, 2001.

[6] Y. X. Lehto, Y. D. Kim, and M. A. Morrison, "The effect of prior destination experience on online information search behaviour," Tourism and Hospitality Research, vol. 6, no. 2, pp.160-178, 2006.

[7] M. Oppermann, "Convention destination images: analysis of association meeting planners' perceptions," Tourism Management, vol. 17, no. 3, pp. 175-182, 1996.

[8] H. Iwamoto, T. Matsuo, T. Fukushima, and N. Komoda, "The self-image of Japanese local cities as a convention host by tourist bureaus," Proceedings of ITC's 15 International Tourism Congress, pp.374-382, 2015.

[9] H. Iwamoto, T. Matsuo, T. Fukushima, and N. Komoda, " Convention bureaus' evaluation of their regional characteristics," Proceedings of 5th IIAI International Congress on Advanced Applied Informatics, pp. 813-818, 2016.

[10]C. Chen, "Applying the analytical hierarchy process (AHP) approach to convention site selection," Journal of Travel Research, vol. 45, no. 2, pp. 167-174, 2006.

[11]G. I. Crouch, and J. R. Brent Ritchie, "Convention site selection research: A review, conceptual model, and propositional framework," Journal of Convention \& Exhibition Management, vol. 1, no. 1, pp. 49-69, 1998.

[12]F. M. Go, and R, Govers, "The Asian perspective: which international conference destinations in Asia are the most competitive?," Journal of Convention \& Exhibition Management, vol. 1, no. 4, pp. 37-50, 1999.

[13]T. J. Lee, "The successful conference venue: perceptions of conference organizers and hotel managers," Event Management, vol. 13, no. 3, pp. 171-180, 2009. 
[14]H. Qu, L. Li, and G. Chu, "The comparative analysis of Hong Kong as an international conference destination in Southeast Asia," Tourism Management, vol. 21, no. 6, pp. 643-648, 2000.

[15]S. S. Kim, Y. Guo, and J. Agrusa, "Preference and Positioning Analyses of Overseas Destinations by Mainland Chinese Outbound Pleasure Tourists," Journal of Travel Research, vol. 44, no. 2, pp. 212-220, 2005. 